\title{
CARDIOVASCULAR MORBIDITY OF INFANTS OF DIABETIC MOTHERS AND ITS ASSOCIATION WITH MATERNAL GLYCAEMIC CONTROL ACCORDING TO HbA1C
}

\author{
Smitha Vijayan'1, Babu Francis Chirayath Antony2, Madathil Govindaraj Geeta ${ }^{3}$ \\ ${ }^{1}$ Trainee, Department of Nephrology, Government Medical College, Kozhikode. \\ ${ }^{2}$ Additional Professor, Department of Paediatrics, Government Medical College, Kozhikode. \\ ${ }^{3}$ Additional Professor, Department of Paediatrics, Government Medical College, Kozhikode.
}

\section{ABSTRACT}

\section{BACKGROUND}

Maternal diabetes mellitus is a relatively common disease that complicates pregnancy and results in an increased incidence of congenital malformations, predominantly congenital heart disease. Glycated haemoglobin (HbA1c) is accepted as an indicator of glycaemic control and correlates with increased risk of congenital anomalies. There is lack of enough studies in India addressing the relationship between the level of glycaemic control in diabetic pregnancy and the incidence of congenital cardiac anomalies.

The objective of this study was to determine the cardiovascular morbidity of infants of diabetic mother and to study the association between the maternal glycaemic control according to HbA1c and the cardiac status of the baby. Another objective was to estimate the frequency of various congenital heart defects in such infants. We also looked at possible relationship between variables like birth weight of the neonates and the need for insulin to control maternal diabetes and incidence of congenital heart disease.

Design- Descriptive study.

Setting- Tertiary care government medical college hospital in Kerala catering to urban and rural population belonging predominantly to the lower socio-economic strata.

\section{MATERIALS AND METHODS}

All the antenatal women with positive Glucose Tolerance Test (GTT) admitted over a period of 8 months were included in the study. They were interviewed using a semistructured questionnaire and HbA1c testing was done within the third postnatal day. The cardiological status of the babies was assessed clinically and by ECHO within the first week after birth.

\section{RESULTS}

Out of total 71 diabetic women, 68(96\%) had gestational diabetes and 3(4\%) had overt diabetes; 14 babies (20\%) were large for gestational age and 4(5\%) were small for gestational age; $47.8 \%$ of Infants of Diabetic Mothers (IDMs) had congenital heart disease and 9.9\% had Asymmetric Septal Hypertrophy (ASH). Among the Congenital Heart Diseases (CHD), maximum were Atrial Septal Defects (ASD) followed by Ventricular Septal Defects (VSD) and Patent Ductus Arteriosus (PDA). The mean birth weight in the group with CHD was significantly higher at $3.22 \mathrm{Kg}$ as against $2.89 \mathrm{Kg}$. The presence of ASH had statistically significant association with higher HbA1c.

\section{CONCLUSION}

This study emphasises the higher frequency of CHD among infants of diabetic mother, ASD being the most common heart disease detected. There was statistically significant association between elevated postnatal HbA1c and diabetic cardiomyopathy.

\section{KEYWORDS}

Infants of Diabetic Mothers, Congenital Heart Disease, Cardiomyopathy, HbA1c.

HOW TO CITE THIS ARTICLE: Vijayan S, Antony BFC, Geeta MG. Cardiovascular morbidity of infants of diabetic mothers and its association with maternal glycaemic control according to HbA1c. J. Evolution Med. Dent. Sci. 2017;6(49):3805-3809, D0I: $10.14260 /$ Jemds/2017/822

\section{BACKGROUND \\ Maternal diabetes mellitus is a relatively common disease that complicates pregnancy and results in an increased incidence of congenital malformations.[1-8] The increased risk of anomalies was predominantly for congenital heart disease (3.4 times higher risk).[9]}

Financial or Other, Competing Interest: None.

Submission 25-05-2017, Peer Review 09-06-2017,

Acceptance 12-06-2017, Published 19-06-2017.

Corresponding Author:

Babu Francis Chirayath Antony,

Additional Professor,

Department of Paediatrics,

Government Medical College,

Kozhikode-673008.

E-mail: babufrancisca@gmail.com

DOI: $10.14260 /$ jemds $/ 2017 / 822$
A glycated haemoglobin (HbA1c) is accepted as an indicator of glycaemic control.[10] The rate of formation of $\mathrm{HbA1c}$ is a function of plasma glucose concentration. ${ }^{[10,11]}$ This reaction being irreversible with red blood cell's lifespan of about 2 - 3 months, HbA1c levels may be used as an estimate of average blood glucose levels over a period of 2 - 3 months prior to testing.[10]

An elevated $\mathrm{HbA1c}$ value is associated with increased risk of adverse pregnancy outcomes like abortions, stillbirth and congenital anomalies.[12-14]

Apart from major cellular events like proliferation and apoptosis, various intracellular metabolic stress conditions like nitrosative and oxidative stress have been demonstrated in animal models and may be extrapolated as the plausible mechanism of inhibition of formation, and later remodelling of endocardial cushions in embryos of diabetic women. ${ }^{[15]}$ 
The initial injury that results in malformations occurs by the seventh week of gestation and ventricular septal defects and transposition of the great vessels are increased five-fold in Infants of Diabetic Mother (IDM).[16] Wide spectrum of congenital heart disease is seen in IDM.

The IDMs are prone to develop hypertrophic cardiomyopathy, best detected by echocardiography, resolving spontaneously as plasma insulin levels normalise.[17,18] In this condition, the most prominent change is Asymmetric Septal Hypertrophy (ASH) with left ventricular outflow obstruction, occasionally aggravated by anterior systolic motion of the mitral valve.[18] Hypertrophic cardiomyopathy is attributed to foetal hyperinsulinaemia, which increases fat and glycogen synthesis and their deposition in the myocardial cells.[19]

This occurs with poor glycaemic control during pregnancy.[20,21] There is possible correlation between high degrees of oxidative stress and the abnormal cardiac remodeling resulting in ASH in IDM.

The Echocardiographic evidence of hypertrophy is noted by late second and early third trimester.[22,23] A positive correlation between HbA1c levels and septal thickness measurements is reported.[24]

The symptomatic infants (5 to 10 percent) typically recover after two to three weeks of supportive care and propranolol, but the echocardiographic findings take 6 to 12 months to resolve.[25] The Inotropic agents worsen cardiac outflow obstruction and hence are contraindicated.[26]

A more diffuse process of hypertrophy and hyperplasia of the myocardial cells resulting in congestive cardiomyopathy occur in some IDMs in association with perinatal asphyxia, hypoglycaemia or hypocalcaemia with echocardiographic evidence of cardiac dilatation and poor contractility, resolving with correction of metabolic derangements.[21]

\section{MATERIALS AND METHODS}

This is a descriptive study in the setting of a Government Medical College, conducted on women coming to medical college hospital for delivery.

\section{Sample}

Women with positive Glucose Tolerance Test (GTT) and their live born neonates.

\section{Inclusion Criteria}

Babies born to mothers with positive GTT.

\section{Exclusion Criteria}

Infants of diabetic mothers born outside medical college hospital, congenital heart disease associated with clinical features suggestive of intrauterine infections and chromosomal anomalies.

All antenatal women with GCT (Glucose Challenge Test) value of greater than or equal to $130 \mathrm{mg} / \mathrm{dL}$ were subjected to GTT (Glucose Tolerance Test) during the study period of 8 months. Women with positive GTT were included in the study. There were a total of 71 diabetic women during this period. The selected mothers were interviewed using a semistructured questionnaire after obtaining informed consent. The details about the duration of diabetes, type of treatment and birth weight of baby were noted.
The cardiological status of the babies was assessed clinically using a set proforma. The clinical findings were confirmed by ECHO within the first week after birth in order to ensure uniformity. ECHO was used to detect structural congenital cardiac malformations as well as diabetic cardiomyopathy. The diabetic cardiomyopathy is indicated by Asymmetric Septal Hypertrophy (ASH). In neonates, the septum was considered hypertrophic if it was $5 \mathrm{~mm}$ or greater. The ASH was diagnosed when the ratio of septal-toLV posterior wall thickness was 1.3 or greater.

The mother's glycaemic control in the last trimester was assessed by HbA1c testing within the third postnatal day. The HbA1c testing was done by High Performance Liquid Chromatography (HPLC), which is currently the method prescribed by the International Federation of Clinical Chemistry (IFCC).

The Qualitative data were analysed using the Pearson's Chi-square test and Fisher exact test. All quantitative data were subjected to the student's ' $t$ ' test and 2-tailed MannWhitney U test; $95 \%$ confidence intervals were assumed. The statistical analysis was done using Epi Info 3.5.

\section{RESULTS}

Out of total 71 diabetic women, 68 (96\%) had gestational diabetes mellitus GDM and $3(4 \%)$ had overt diabetes. The majority of diabetic women, 56 (79\%) were on insulin therapy and the rest 15 (21\%) were on diet control. In the weight wise distribution, maximum number of babies 31 belonged to $3.0-3.499 \mathrm{~kg}$ followed by 22 babies in the category of $2.5-2.99 \mathrm{~kg}$. Only 1 baby weighed less than $2 \mathrm{~kg}$. Most of the babies, 53 (75\%) were appropriate for gestational age; $14(20 \%)$ were large for gestational age and only $4(5 \%)$ were small for gestational age.

The mean $\mathrm{HbA1c}$ was $6.19 \%$. Out of 71 neonates 34 (47.8\%) had CHD, 7 (9.9\%) had ASH and diffuse ventricular hypertrophy in 12 (16.9\%).

\begin{tabular}{|c|c|c|c|}
\hline & $\begin{array}{c}\text { With CHD } \\
(\mathbf{n = 3 4 )}\end{array}$ & $\begin{array}{c}\text { Without CHD } \\
(\mathbf{n = 3 7})\end{array}$ & P value \\
\hline $\begin{array}{c}\text { Mean } \\
\text { Postnatal } \\
\text { HbA1c }\end{array}$ & $\begin{array}{c}6.2147 \\
\text { S.D. }=(0.66703)\end{array}$ & $\begin{array}{c}6.1676 \\
\text { S.D. }=(1.16023)\end{array}$ & $\begin{array}{c}0.836 \\
\text { (t-test })\end{array}$ \\
\hline $\begin{array}{c}\text { Mean Birth } \\
\text { Weight (kg) }\end{array}$ & $\begin{array}{c}3.2206 \\
\text { S.D. }=(0.35995)\end{array}$ & $\begin{array}{c}2.8892 \\
\text { S.D. }=(0.47946)\end{array}$ & $\begin{array}{c}0.002 \\
\text { (t-test })\end{array}$ \\
\hline \multicolumn{4}{|c|}{ Table I. Comparison of Mothers of Babies With and } \\
Without CHD
\end{tabular}

$\mathrm{CHD}=$ Congenital Heart Disease

While $94.1 \%$ of those 34 diabetic mothers whose neonates having CHD needed insulin, only $64.9 \%$ of the remaining needed insulin for diabetic control with a ' $\mathrm{P}$ ' value of 0.0024 (Fisher exact).

\begin{tabular}{|c|c|c|c|}
\hline & $\begin{array}{c}\text { With ASH } \\
(\mathbf{n = 7})\end{array}$ & $\begin{array}{c}\text { Without ASH } \\
(\mathbf{n = 6 4 )}\end{array}$ & P value \\
\hline $\begin{array}{c}\text { Mean } \\
\text { Postnatal } \\
\text { HbA1c }\end{array}$ & $\begin{array}{c}7.7143 \\
\text { S.D. }=(1.15676)\end{array}$ & $\begin{array}{c}6.0234 \\
(\text { S.D. }=0.76754)\end{array}$ & $\begin{array}{c}0.000 \\
\text { (t-test) }\end{array}$ \\
\hline $\begin{array}{c}\text { Mean Birth } \\
\text { Weight (kg) }\end{array}$ & $\begin{array}{c}3.0143 \\
\text { S.D.=(0.53675) }\end{array}$ & $\begin{array}{c}3.0516 \\
\text { S.D. }=(0.45004)\end{array}$ & $\begin{array}{c}0.839 \\
\text { (t-test) }\end{array}$ \\
\hline
\end{tabular}

Table II. Comparison of Mothers of Babies With and Without ASH 
ASH= Asymmetric Septal Hypertrophy

While all the 7 diabetic mothers whose neonates having ASH needed insulin, only $76.6 \%$ of the remaining needed insulin for diabetic control with a ' $\mathrm{P}$ ' value of 0.1743 (Fisher exact).



Figure I. Types of Cardiac Anomalies detected by Echocardiography

Among the congenital heart disease in our babies, maximum was Atrial Septal Defect (ASD) followed by Ventricular Septal Defect (VSD) and Patent Ductus Arteriosus (PDA).

\section{DISCUSSION}

In common with most previous epidemiological studies, we defined CHD as a "gross structural abnormality of the heart or intrathoracic great vessels that is actually or potentially of functional importance." Hence, we excluded Patent Foramen Ovale (PFO), as it is usually of no haemodynamic significance unless another cardiac anomaly is causing increased right atrial pressure and thus right-to-left shunt through the PFO.

A prospective study of cardiovascular malformations in infants of diabetic mothers conducted by Wren et al in the Northern Health Region of England during the period 1995 2000, and a study in the Netherlands conducted at the Yale New Haven Medical Centre from 1988 - 1998 showed a prevalence of $3.6 \%$ and $3 \%$ respectively.[27,28] In our study, $47.8 \%$ of the infants of diabetic mothers had congenital heart disease. This is a high figure compared to the western statistics. The prevalence of congenital heart disease has varied widely, probably due to the different methods of investigations used. Both the above-mentioned European studies have excluded atrial septal defect undergoing spontaneous closure in infancy. Moreover, the population included in both the Western studies are patients with type 1 diabetes. Out of 1 to $14 \%$ of all pregnancies complicated by abnormal glycaemic control, $80 \%$ are due to gestational diabetes as compared to pregestational diabetes. That is, these studies have not considered the major group of GDM who constitute the bulk of poor glycaemic control in pregnancy. If babies born to mothers with GDM had also been included in the European studies, probably the prevalence of congenital heart disease would have been higher.
Unlike the other two above-mentioned studies, study done by S Ullmo et al in Switzerland during the period 2003 2005 included a population of mothers with all types of diabetes: Type 1, Type 2 and GDM. GDM is found in $95.8 \%$ in our study as compared to $62.06 \%$ in the study by S Ullmo et al. The mean $\mathrm{HbA1c}$ is $6.19 \%$ in the present study and $5.8 \%$ in the Swiss study. The infants of diabetic mothers with CHD in our study are high at $47.8 \%$ as against $6.5 \%$ in the Swiss study. The difference may probably be due to the fact that pregnancies are planned and are reported to a central register, especially in high risk cases in the West. Strict glycaemic control is maintained in the peri-conceptional period as well as throughout pregnancy by regular monitoring and treatment. This is important, as the abnormal maternal metabolic milieu has been implicated as a teratogenic factor along with genetic susceptibility.

The HbA1c measurement in our study is done within 3 days after delivery. We could not do the HbA1c measurement in the first trimester due to practical reason, as our institution is a tertiary care hospital to which difficult cases are referred mostly around second or third trimester. The mean $\mathrm{HbA} 1 \mathrm{c}$ in the mothers of babies with CHD is above normal at $6.2 \%$ (Table I). The higher HbA1c levels in cases with cardiac malformations support the association of suboptimal glycaemic control and the occurrence of CHD as previously reported by Miller E et al,[12] Leslie RD et al[13] and Greene MF et al.[14]

The HbA1c level is proportional to average blood glucose concentration over the previous four weeks to three months. Hence, the postnatal HbA1C which we have measured reflects the glycaemic control in the last trimester. The level of metabolic control in mother during organogenesis can be ascertained only by $\mathrm{HbA1c}$ in the first trimester. Therefore, the statistically insignificant association between the postnatal HbA1c and the congenital heart disease in this study is expected. The mean birth weight in the group with CHD is higher at $3.22 \mathrm{~kg}$ as against $2.89 \mathrm{~kg}$ (Table I). This finding too is statistically significant.

Hyperglycaemia in third trimester is responsible for cellular proliferation, macrosomia and cardiomyopathy. The mean postnatal $\mathrm{HbA1c}$ is associated with the occurrence of cardiomyopathy and asymmetric septal hypertrophy. This association is demonstrated to be statistically significant in the present study (Table II). Similar results are shown by Halliday HL.[29]

ASD in the present study is high at $22 \%$ and the high incidence of conotruncal septation and bulboventricular looping abnormalities detected in other studies ${ }^{[30,31,32,33]}$ has not been found in the present study [Figure I].

The wide difference noted between this study and other studies may perhaps be due to the following reasons. All the other studies have been done before and around 1990. The most recent advance in ECHO like Doppler has been used extensively only since the nineties. Therefore, the sensitivity of ECHO has increased tremendously. Many minutes ASDs, which might have been missed earlier are now being picked up. Although, we have excluded PFO in our study, there is always a possibility of difficulty in distinguishing between PFO and small ASD of less than $3 \mathrm{~mm}$ in diameter. We have not done followup study of these babies to exclude ASDs, which undergo spontaneous closure unlike the other studies. All these factors might have contributed to the high frequency 
of ASD in our study. The frequency of VSD and PDA are similar in the present study and other studies. VSD is detected in $10 \%$ of IDMs in our study, which is also a high figure.

\section{What this Study Adds}

Poor glycaemic control in late pregnancy as indicated by a positive GTT and elevated postnatal HbA1c are surrogate markers of poor glycaemic control during all trimesters, and there is statistically significant association with the development of diabetic cardiomyopathy. The present study has shown higher incidence of CHD among IDM.

\section{Limitations of the Study}

HbA1c measurement could not be done in the periconceptional period and first trimester. No followup study of the babies with CHD was done. Hence, comment about the transient nature of diabetic cardiomyopathy and ASDs which undergo spontaneous closure have not been possible.

There is lack of enough studies in India regarding the pattern of CHD in infants of diabetic mother, and the level of glycaemic control in diabetic pregnancy. More research is warranted in this field in our setup, as this is a preventable cause of cardiovascular morbidity.

\section{CONCLUSION}

This study emphasises the higher frequency of congenital heart disease among infants of diabetic mother. The atrial septal defect is the most common heart disease detected. The high incidence of conotruncal septation and bulboventricular looping abnormalities described classically in IDM has not been found in the present study.

There is statistically significant association between elevated postnatal HbA1c and development of ASH. Due to teratogenicity of the abnormal maternal metabolic milieu, strict glycaemic control is to be ensured during organogenesis and thereafter. Hence, HbA1c monitoring in the peri-conceptional period as well as throughout pregnancy in overt diabetes and in GDM from the time of confirmation of diagnosis is suggested.

\section{REFERENCES}

[1] Ylinen K, Aula P, Stenman UH, et al. Risk of minor and major fetal malformations in diabetics with haemoglobin A1c values in early pregnancy. Br Med J 1984;289(6441):345-6.

[2] Molsted-Pedersen L, Tygstrup I, Pedersen J. Congenital malformations in newborn infants of diabetic women. Correlation with maternal diabetic vascular complications. Lancet 1964;1(7343):1124-6.

[3] Kucera J. Rate and type of congenital anomalies among offspring of diabetic women. J Reprod Med 1971;7(2):73-82.

[4] Miodovnik M, Mimouni F, Dignan PS, et al. Major malformations in infants of IDDM women. Vasculopathy and early first-trimester poor glycemic control. Diabetes Care 1988;11(9):713-8.

[5] Casson IF, Clarke CA, Howard CV, et al. Outcomes of pregnancy in insulin dependent diabetic women: results of a five year population cohort study. Br Med J 1997;315(7103):275-8.
[6] Lisowski LA, Verheijen PM, Copel JA, et al. Congenital heart disease in pregnancies complicated by maternal diabetes mellitus. An international clinical collaboration, literature review and meta-analysis. Herz 2010;35(1):19-26.

[7] Kalhan SC, Parimi PS, Lindsay CA. Pregnancy complicated by diabetes mellitus. In: Fanaroff AA, Martin RJ. eds. Neonatal-perinatal medicine: diseases of the fetus and infant. $7^{\text {th }}$ edn. Philadelphia: Mosby 2002:1357-62.

[8] Georgieff MK. Therapy of infants of diabetic mothers. In: Burg FD, Ingelfinger JR, Wald ER, et al. eds. Current pediatric therapy. $15^{\text {th }}$ edn. Philadelphia: WB Saunders 1995:793-803.

[9] Macintosh MC, Fleming KM, Bailey JA, et al. Perinatal mortality and congenital anomalies in babies of women with type 1 or type 2 diabetes in England, Wales and Northern Ireland: population based study. BMJ 2006;333(7560):177.

[10] Makris K, Spanou L, Rambaouni-Antoneli A, et al. Relationship between mean blood glucose and glycated haemoglobin in Type 2 diabetic patients. Diabet Med 2008;25(2):174-8.

[11] Cohen RM, Franco RS, Khera PK, et al. Red cell life span heterogeneity in hematologically normal people is sufficient to alter HbA1c. Blood 2008;112(10):428491.

[12] Miller E, Hare JW, Cloherty JP, et al. Elevated maternal hemoglobin $\mathrm{A} 1 \mathrm{C}$, in early pregnancy and major congenital anomalies in infants of diabetic mothers. N Engl J Med 1981;304(22):1331-4.

[13] Leslie RDG, Pyke DA, John PN, et al. Hemoglobin A1 in diabetic pregnancy. Lancet 1978;2:958-9.

[14] Greene MF. Spontaneous abortions and major malformations in women with diabetes mellitus. Semin Reprod Endocrinol 1999;17(2):127-36.

[15] Zhao A, Reece EA. New concepts in diabetic embryopathy. Clin Lab Med 2013;33(2):207-33.

[16] Sutton DM, Han CS, Werner EF, et al. Diabetes mellitus in pregnancy. Neo reviews. 2017;18(1):e33.

[17] Ullmo S, Vial Y, di Bernardo S, et al. Pathologic ventricular hypertrophy in the offspring of diabetic mothers: a retrospective study. Eur Heart J 2007;28(11):1319-25.

[18] Veille JC, Sivakoff M, Hanson R, et al. Interventricular septal thickness in fetuses of diabetic mothers. Obstet Gynecol 1992;79(1):51-4.

[19] Allan CJ, Argyropoulos G, Bowker M, et al. Gestational diabetes mellitus and gene mutations which affect insulin secretion. Diabetes Res Clin Pract 1997;36(3):135-41.

[20] Mace S, Hirschfield SS, Riggs T, et al. Echocardiographic abnormalities in infants of diabetic mothers. J Pediatr 1979;95(6):1013-9.

[21] Braunwald E. Heart disease: a textbook of cardiovascular medicine. Philadelphia: Saunders 1997.

[22] Hornberger LK. Maternal diabetes and the fetal heart. Heart 2006;92(8):1019-21. 
[23] Elmekkawi SF, Mansour GM, Elsafty MSE, et al. prediction of fetal hypertrophic cardiomyopathy in diabetic pregnancies compared with postnatal outcome. Clin Med Insights Women's Health 2015;8:39-43.

[24] Nashaat EH, Mansour GM. Uncontrolled diabetes mellitus and fetal heart. J Am Coll Cardiol 1998;32:492-8.

[25] Way GL, Wolfe RR, Eshaghpour E, et al. The natural history of hypertrophic cardiomyopathy in infants of diabetic mothers. J Pediatr 1979;95(6):1020-5.

[26] Denfield SW, Gajarski RJ, Towbin JA. Cardiomyopathies. In: Garson AG, Bricker JT, Fisher DJ, et al. eds. The science and practice of pediatric cardiology. Baltimore: Williams and Wilkins 1998; p. 1851.

[27] Wren C, Birrell G, Hawthorne G. Cardiovascular malformations in infants of diabetic mothers. Heart 2003;89(10):1217-20.

[28] Evers IM, de Valk HW, Mol BWJ, et al. Macrosomia despite good glycemic control in type 1 diabetic pregnancy: results of a nationwide study in the Netherlands. Diabetologia 2002;45(11):1484-9.
[29] Halliday HL. Hypertrophic cardiomyopathy in infants of poorly-controlled diabetic mothers. Arch Dis Child 1981;56(4):258-63.

[30] Mills JL, Knopp RH, Simpson JL, et al. Lack of relation of increased malformation rates in infants of diabetic mothers to glycemic control during organogenesis. $\mathrm{N}$ Engl J Med 1988;318(11):671-6.

[31] Rowland TW, Hubbell JP, Nadas AS. Congenital heart disease in infants of diabetic mothers. J Paediatr 1973;83(5):815-20.

[32] Ferencz C, Rubin JD, McCarter RJ, et al. Maternal diabetes and cardiovascular malformations: predominance of double outlet right ventricle and truncus arteriosus. Teratology 1990;41(3):319-26.

[33] Becerra JE, Khoury MJ, Cordero JF, et al. Diabetes mellitus during pregnancy and the risks for specific birth defects: a population-based case-control study. Pediatrics 1990;85(1):1-9. 